\title{
Influência de fungos micorrízicos arbusculares sobre o crescimento de dois genótipos de aceroleira (Malpighia emarginata D.C.) $)^{(1)}$
}

\author{
Cynthia Maria Carneiro Costa ${ }^{(2)}$, Leonor Costa Maia ${ }^{(3)}$, Uided Maaze Tiburcio Cavalcante(4) \\ e Rejane Jurema Mansur Custódio Nogueira ${ }^{(4)}$
}

\begin{abstract}
Resumo - O objetivo deste trabalho foi avaliar o efeito da inoculação de fungos micorrízicos arbusculares (FMA) no crescimento da aceroleira (Malpighia emarginata D.C.). Estacas semi-lenhosas de dois genótipos de aceroleira (Barbados e Miró), com dois pares de folhas, foram plantadas para enraizamento das mudas. Após dois meses, montou-se um experimento em telado, inoculando dois isolados de FMA (Gigaspora margarita Becker \& Hall e Glomus etunicatum Becker \& Gerdemann) nessas mudas, em solo com $3 \mathrm{mg} / \mathrm{dm}^{3}$ de fósforo. Ao término do experimento (110 dias), observou-se que a inoculação de FMA proporcionou maior altura, aumentou a biomassa seca da parte aérea e a área foliar, e evidenciou correlações positivas entre algumas características de crescimento da planta e o número de esporos de FMA, em comparação com as plantas não colonizadas. Melhores respostas de crescimento foram obtidas nos dois genótipos com a inoculação de G. margarita. A concentração de P na parte aérea das plantas não variou significativamente entre os tratamentos com inoculação. A associação com FMA reduziu em pelo menos dois meses o tempo de produção de mudas dos dois genótipos de aceroleira.
\end{abstract}

Termos para indexação: fruteiras, inoculação, material de propagação, mudas.

Effect of arbuscular mycorrhizal fungi on growth of two genotypes of Malpighia emarginata D.C.

\begin{abstract}
The objective of this research was to evaluate the effect of inoculation with arbuscular mycorrhizal fungi (AMF) on growth of seedlings of Malpighia emarginata D.C. Stakes of these two genotypes (Barbados and Miró), with two pairs of leaves, were planted for rooting of the seedlings. After two months, a greenhouse experiment was performed, inoculating two AMF species (Gigaspora margarita Becker \& Hall and Glomus etunicatum Backer \& Gerdemann) under the seedlings, in soils with $3 \mathrm{mg} / \mathrm{dm}^{3}$ phosphorus. At the end of the experiment (110 days), it was observed that the inoculation with AMF enhanced height, shoot dry mass, leaf area, and presented positive correlations among some plant growth characters and among those and number of AMF spores, in comparison with the uninoculated controls. The inoculation with G. margarita produced higher growth responses for both genotypes. The $\mathrm{P}$ concentration on the shoots did not vary among treatments. The symbiosis with AMF reduced at least in two months the time for seedlings production on both genotypes of Malpighia emarginata.
\end{abstract}

Index terms: fruit crops, inoculation methods, propagation materials, scions.

(1) Aceito para publicação em 29 de agosto de 2000 .

Extraído da dissertação de mestrado, apresentada pela primeira autora à Universidade Federal de Pernambuco (UFPE), Recife, PE. Financiado pelo CNPq

(2)UFPE, Centro de Ciências Biológicas (CCB), Dep. de Micologia, Av. Prof. Nelson Chaves, s/n, CEP 50670-420 Recife, PE. E-mail: cmccosta@yahoo.com

(3)UFPE, CCB, Dep. de Micologia. Bolsista do CNPq. E-mail: leonorcmaia@hotmail.com

(4)Universidade Federal Rural de Pernambuco (UFRPE), Dep de Biologia, Rua Dom Manoel de Medeiros, s/n, CEP 52171-900 Recife, PE. E-mail: umaaze@ig.com.br, alisboa@elogica.com.br

\section{Introdução}

A aceroleira é uma cultura em pleno desenvolvimento, não só pelo altíssimo teor de vitamina $\mathrm{C}$ dos frutos (Gonzaga Neto \& Soares, 1994), como também pela crescente perspectiva de exportação, pois a região Nordeste oferece condições de produção durante a maior parte do ano.

Os fungos micorrízicos arbusculares (FMA) são importantes para a nutrição e o crescimento de espécies frutíferas (Weber \& Amorim, 1994). Na fase de produção de mudas, a utilização de FMA tem demonstrado ser de grande potencial para o desen- 
volvimento mais eficiente (Jaizme-Vega \& Azcón, 1995), minimizando o uso de fertilizantes e antecipando o tempo de transplantio ao campo (Cavalcante, 1999).

Aspectos da relação fungo-planta devem ser considerados para o estabelecimento da simbiose micorrízica, uma vez que efeitos da variação genotípica sobre a colonização têm sido relatados em amplo número de espécies de plantas (GianinazziPearson, 1996).

Chu (1993) observou que a inoculação de FMA em aceroleiras promoveu alguns parâmetros de crescimento da planta, além de acelerar o tempo de transplantio ao campo.

Até agora foram realizados poucos trabalhos sobre a associação entre FMA e aceroleiras; há necessidade de se ampliar as pesquisas nesta área, considerando os benefícios reconhecidamente trazidos a outras fruteiras, pela micorrização.

O objetivo deste trabalho foi avaliar o efeito da simbiose micorrízica no desenvolvimento de dois genótipos de aceroleira, visando identificar uma combinação fungo x planta mais promissora para utilização em campo.

\section{Material e Métodos}

O experimento foi concluído em casa de vegetação, no Departamento de Biologia da Universidade Federal Rural de Pernambuco, e no Laboratório de Micorrizas da Universidade Federal de Pernambuco.

O substrato utilizado foi um Latossolo Amarelo distrófico argissólico, coletado na profundidade de 0 a $20 \mathrm{~cm}$ e desinfestado com brometo de metila. A análise química do solo revelou as seguintes características: $\mathrm{pH} \mathrm{5,4;} \mathrm{P}$, $3 \mathrm{mg} / \mathrm{dm}^{3} ; \mathrm{Al}, 0,2 \mathrm{cmol}_{\mathrm{c}} / \mathrm{dm}^{3} ; \mathrm{Na}, 0,12 \mathrm{cmol}_{\mathrm{c}} / \mathrm{dm}^{3} ; \mathrm{Ca}$, $1,4 \mathrm{cmol}_{\mathrm{c}} / \mathrm{dm}^{3} ; \mathrm{Mg}, 0,8 \mathrm{cmol}_{\mathrm{c}} / \mathrm{dm}^{3} ; \mathrm{K}, 0,15 \mathrm{cmol}_{\mathrm{c}} / \mathrm{dm}^{3}$.

Para o preparo das mudas, foram utilizadas estacas semi-lenhosas, com dois pares de folhas, dos genótipos Barbados e Miró, fornecidas pela Estação Experimental de Carpina (UFRPE). As estacas foram plantadas em copos de plástico de $200 \mathrm{~mL}$ com solo previamente desinfestado e acondicionadas em câmara úmida para enraizamento.

Como inóculo foram utilizados isolados de Gigaspora margarita Becker \& Hall e de Glomus etunicatum Becker \& Gerdemann, cedidos pela Embrapa-Centro Nacional de Pesquisa de Agrobiologia, e registrados na UFPE sob os números 02 e 08 , respectivamente, sendo multiplicados em grama baiana (Paspalum notatum Flügge).

Pesq. agropec. bras., Brasília, v. 36, n. 6, p. 893-901, jun. 2001
Após 56 dias de plantio, as estacas enraizadas foram transferidas dos copos para potes de plástico com capacidade para $2 \mathrm{~kg}$ de solo e na ocasião foi feita a inoculação de 200 esporos de cada fungo micorrízico por pote, sobre as raízes das plantas. Os tratamentos sem inoculação receberam $2 \mathrm{~mL}$ da solução do filtrado (1:10 solo:água, v/v) dos solos utilizados na extração dos esporos para restabelecer a microbiota original (Araújo et al., 1994), com exceção dos esporos de FMA.

O delineamento experimental foi em blocos ao acaso, com dois genótipos de aceroleiras (Barbados e Miró) x três tratamentos de inoculação (Gigaspora margarita, Glomus etunicatum e sem inoculação), com oito repetições. Diariamente foram registrados os valores de temperatura e umidade relativa do ar, através de termoigrômetro (TFA, Alemanha), os quais corresponderam à temperatura do ar com máxima de $32,9^{\circ} \mathrm{C}$ e mínima de $26,2^{\circ} \mathrm{C}$ e umidade relativa do ar com máxima e mínima de $86 \%$ e $59 \%$, respectivamente, durante o período do experimento, em telado.

Aos 110 dias após a inoculação, as plantas foram coletadas e avaliadas quanto ao crescimento (altura média, área foliar, biomassa seca), concentração de P na parte aérea, porcentagem de raiz colonizada, densidade de esporos na rizosfera, incrementos e correlações. Após a coleta, determinou-se a área foliar (Benincasa, 1988), e em seguida, toda a parte aérea foi colocada em estufa com circulação de ar, a $65^{\circ} \mathrm{C}$, até atingir peso constante, para determinação da biomassa seca e do conteúdo de $\mathrm{P}$ na parte aérea. Para determinação da concentração do P, a biomassa foi triturada em moinho tipo Willey, pesada, e submetida a digestão nitroperclórica, e, posteriormente, analisada através da leitura em fotocolorímetro (Sarruge \& Haag, 1974).

Para determinação da porcentagem de colonização, as raízes foram clarificadas e coradas com $0,05 \%$ de Azul-deTrypan em lactoglicerol (Phillips \& Hayman, 1970, modificado) e a avaliação da colonização foi feita em microscópio estereoscópico, seguindo a técnica de interseção dos quadrantes (Giovannetti \& Mosse, 1980).

Esporos foram extraídos a partir de amostras de $50 \mathrm{~g}$ de solo de cada tratamento, por peneiramento úmido (Gerdemann \& Nicolson, 1963) seguido de centrifugação em água e sacarose a $40 \%$ (Jenkins, 1964). Os esporos recolhidos em peneiras de 62 e $44 \mu \mathrm{m}$ foram transferidos para placa canaletada e contados sob microscópio estereoscópico (45X).

Os dados obtidos foram submetidos a análise de variância, utilizando-se o programa SANEST, e as médias, comparadas pelo teste de Tukey a $5 \%$ de probabilidade. Para a análise, alguns dados foram transformados: colonização de raízes (arco sen $\sqrt{\% / 100})$ e densidade de esporos $(\log X+1)$. 
Além dos estudos isolados, foram realizados estudos de correlação simples, pelo programa estatístico NTIA/ Embrapa, de acordo com o modelo de Karl Peterson (Ribeiro, 1970) para verificar possíveis relações entre uma variável e as demais.

Nestes estudos foram considerados os níveis de significância estatística de $\mathrm{P}<0,01$ e $\mathrm{P}<0,05$, e o grau de relação (r), que pode ser positivo ou negativo, e seus valores máximos foram representados, respectivamente, por $\mathrm{r}=1$ e $\mathrm{r}=-1$ (Ribeiro, 1970).

\section{Resultados e Discussão}

Foram observadas diferenças significativas na altura das plantas a partir dos 56 dias após a inoculação do FMA (Figura 1), com dados médios dos dois genótipos estudados. Após 56 dias da inoculação de G. margarita, as plantas apresentaram maior altura que as plantas sem inoculação; e com 77 dias, a altura também era superior à das plantas que receberam inóculo de G. etunicatum. Só após 84 dias as plantas que receberam inóculo de G. etunicatum apresentaram maior altura do que as sem inoculação.

$\mathrm{Na}$ análise dos genótipos, independentemente da inoculação dos FMA, só foram constatadas diferenças significativas na altura aos 110 dias (Figura 2). Ao término do experimento, a altura das plantas-con- trole do genótipo Miró não passou de 5,07 $\mathrm{cm}$ e de $6,66 \mathrm{~cm}$ no genótipo Barbados (Tabela 1 ). Nos tratamentos colonizados, as plantas do genótipo Miró não diferiram entre si, e apresentaram altura média ideal para o transplantio para o campo, pois a altura ideal para o transplantio, segundo Chu (1993), está entre 30 e $40 \mathrm{~cm}$, sendo necessário um período de seis a oito meses para que esta seja alcançada. O tempo de produção das mudas, nos resultados aqui obtidos, correspondeu aproximadamente à metade do tempo referido por Chu (1993).

A análise de variância evidenciou regressão linear nos tratamentos de inoculação, em razão do estádio de desenvolvimento das mudas de aceroleira; observou-se que a altura aumentou gradativamente até os 110 dias (Figura 3).

Em todos os parâmetros de crescimento da planta analisados (altura, biomassa seca da parte aérea e área foliar), a melhor resposta com a inoculação foi observada nas plantas do genótipo Miró, independentemente do fungo inoculado; em relação ao genótipo Barbados, os melhores resultados ocorreram quando as plantas foram colonizadas por G. margarita. Diferenças entre as plantas colonizadas por G. etunicatum e as sem inoculação só ocorreram na colonização das raízes (Tabela 1 ). Benefícios na altura e biomassa seca da parte aérea foram

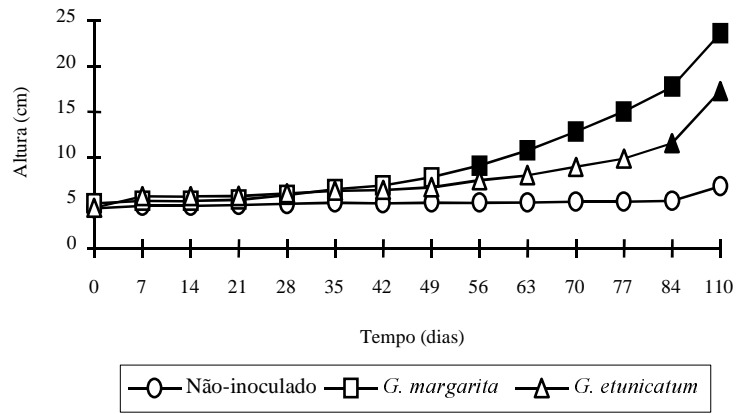

Figura 1. Efeito da inoculação de Gigaspora margarita e Glomus etunicatum na altura média dos dois genótipos de aceroleira (Malpighia emarginata D.C.), durante 110 dias de experimento em telado. Os símbolos preenchidos indicam diferença significativa entre os tratamentos, pelo teste de Tukey a $5 \%$ de probabilidade.

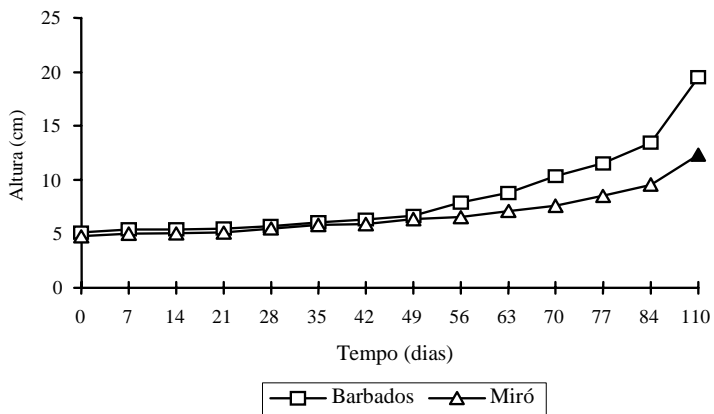

Figura 2. Altura dos genótipos Barbados e Miró de aceroleira (Malpighia emarginata D.C.) durante os 110 dias de experimento. O símbolo preenchido em preto indica diferença significativa entre os tratamentos, pelo teste de Tukey a $5 \%$ de probabilidade.

Pesq. agropec. bras., Brasília, v. 36, n. 6, p. 893-901, jun. 2001 
Tabela 1. Efeito da inoculação dos fungos micorrízicos arbusculares (FMA) Gigaspora margarita (Gm) e Glomus etunicatum (Ge) sobre a altura, biomassa seca da parte aérea (BSPA), área foliar, densidade de esporos (DE) e colonização das raízes, nos genótipos de aceroleira Barbados (B) e Miró (M), aos 110 dias após a inoculação(1).

\begin{tabular}{|c|c|c|c|c|c|c|c|c|c|c|}
\hline \multirow[t]{2}{*}{ FMA } & \multicolumn{2}{|c|}{ Altura $(\mathrm{cm})$} & \multicolumn{2}{|c|}{ BSPA (g) } & \multicolumn{2}{|c|}{ Área foliar } & \multicolumn{2}{|c|}{ DE (n $/ 50 \mathrm{~g}$ de solo) } & \multicolumn{2}{|c|}{ Colonização (\%) } \\
\hline & B & $\mathrm{M}$ & B & $\mathrm{M}$ & $\mathrm{B}$ & $\mathrm{M}$ & $\mathrm{B}$ & $\mathrm{M}$ & $\mathrm{B}$ & $\mathrm{M}$ \\
\hline $\mathrm{Gm}$ & $21,75 \mathrm{aA}$ & $25,55 \mathrm{aA}$ & $2,71 \mathrm{aA}$ & $3,71 \mathrm{aA}$ & $236,81 \mathrm{aA}$ & 293,69aA & $149,00 \mathrm{aB}$ & $497,87 \mathrm{aA}$ & $62,75 \mathrm{aB}$ & $76,62 \mathrm{aA}$ \\
\hline $\mathrm{Ge}$ & $8,58 \mathrm{bB}$ & $27,87 \mathrm{aA}$ & $0,70 \mathrm{bB}$ & $3,73 \mathrm{aA}$ & $19,88 \mathrm{bB}$ & $351,30 \mathrm{aA}$ & $36,87 \mathrm{bA}$ & $48,90 \mathrm{bA}$ & $5,18 \mathrm{bB}$ & $50,02 \mathrm{bA}$ \\
\hline $\mathrm{Si}$ & $6,66 \mathrm{bA}$ & $5,07 \mathrm{bA}$ & $0,57 \mathrm{bA}$ & $0,54 \mathrm{bA}$ & $6,54 \mathrm{bA}$ & $18,60 \mathrm{bA}$ & $7,88 \mathrm{cA}$ & $12,42 \mathrm{cA}$ & $2,06 \mathrm{bA}$ & $1,70 \mathrm{cA}$ \\
\hline
\end{tabular}

${ }^{(1)}$ Médias seguidas da mesma letra, minúsculas na coluna e maiúsculas na linha, não são significativamente diferentes pelo teste de Tukey a $5 \%$ de probabilidade.

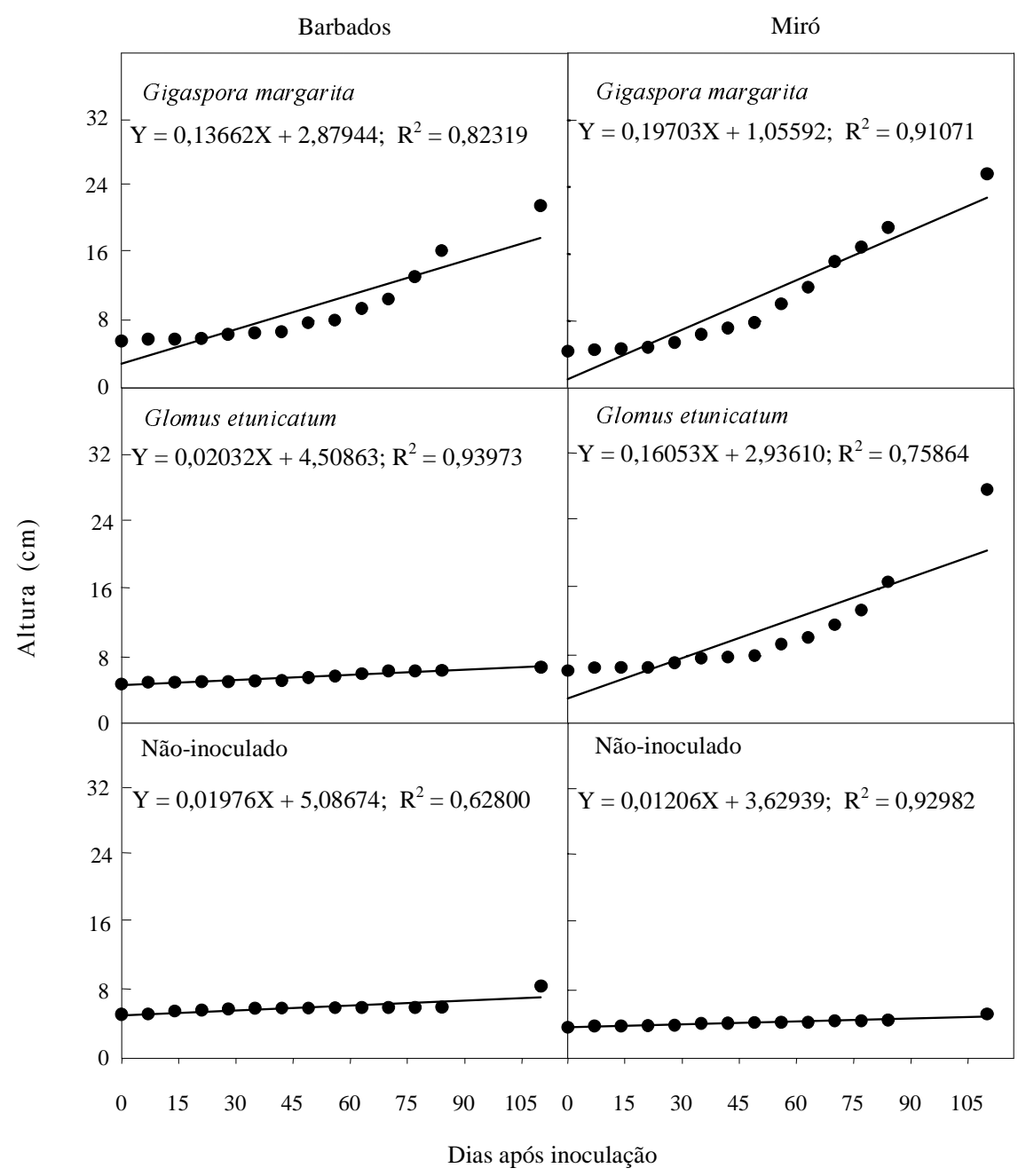

Figura 3. Altura das mudas dos genótipos Barbados e Miró de aceroleira em razão da inoculação dos fungos Gigaspora margarita e Glomus etunicatum, e do estádio de desenvolvimento das plantas. 
alcançados com G. etunicatum, em mamoeiro 'Solo' (Weber \& Amorim, 1994). Respostas contrárias, com a inoculação, foram observadas por Silva \& Siqueira (1991) em abacateiro, onde a altura das mudas não diferiu entre os tratamentos inoculados e os não inoculados.

Os valores de biomassa seca da parte aérea nos dois genótipos de aceroleira colonizados por G. margarita foram semelhantes aos encontrados por Chu (1993), na mesma fruteira. A associação com G. etunicatum resultou em maior biomassa que a das plantas controle no genótipo Miró. Não houve diferença estatística entre os valores de área foliar das mudas do genótipo Miró colonizadas; no entanto, as do genótipo Barbados foram mais beneficiadas pela associação com G. margarita (Tabela 1). Influência positiva da inoculação de FMA também foi observada na área foliar de maracujazeiro 'amarelo' (Cavalcante, 1999).

Diferenças nas respostas de crescimento entre os genótipos foram observadas com a inoculação de G. etunicatum; as mudas do genótipo Miró alcançaram maiores valores de altura, biomassa seca da parte aérea e área foliar (Tabela 1).

Houve incremento em todos os parâmetros de crescimento observados ao final do experimento (Figura 4). Quando colonizadas, tanto por G. etunicatum como por G. margarita, as plantas do genótipo Miró tiveram maior incremento na altura (449,70\% e 403,94\%, respectivamente) do que as testemunhas. No genótipo Barbados, porém, maior incremento ocorreu com inoculação de G. margarita (226,57\%). Os maiores valores de incremento em área foliar foram alcançados nas plantas do genótipo Barbados quando colonizadas por G. margarita (3.520,94\%). Os incrementos observados no genótipo Miró foram proporcionados similarmente pelos dois tratamentos de inoculação. Com relação à biomassa seca da parte aérea, maiores incrementos foram observados com as plantas do genótipo Miró. As plantas do genótipo Barbados tiveram maior incremento de biomassa seca quando colonizadas por G. margarita; a colonização por G. etunicatum proporcionou incremento insignificante (Figura 4).

Em aceroleiras micorrizadas, Chu (1993) obteve incrementos de 2,6 vezes na altura e de 9,2 vezes na produção de biomassa seca, em relação às plantas sem inoculação. Diferenças no incremento em relação à micorrização também foram observadas em plantas de tangerina 'Cleópatra' (Cardoso \& Lambais, 1993) e em mudas de maracujazeiro ‘amarelo' (Cavalcante, 1999). O mesmo foi relatado por GonzálezChávez \& Ferrera-Cerrato (1990), para mudas de morangueiros, sendo essas dependentes do FMA inoculado e da cultivar.

A concentração de $\mathrm{P}$ na parte aérea das plantas não diferiu significativamente entre os genótipos (em Barbados, 2,03 g/kg e em Miró, 1,71 g/kg), conside-

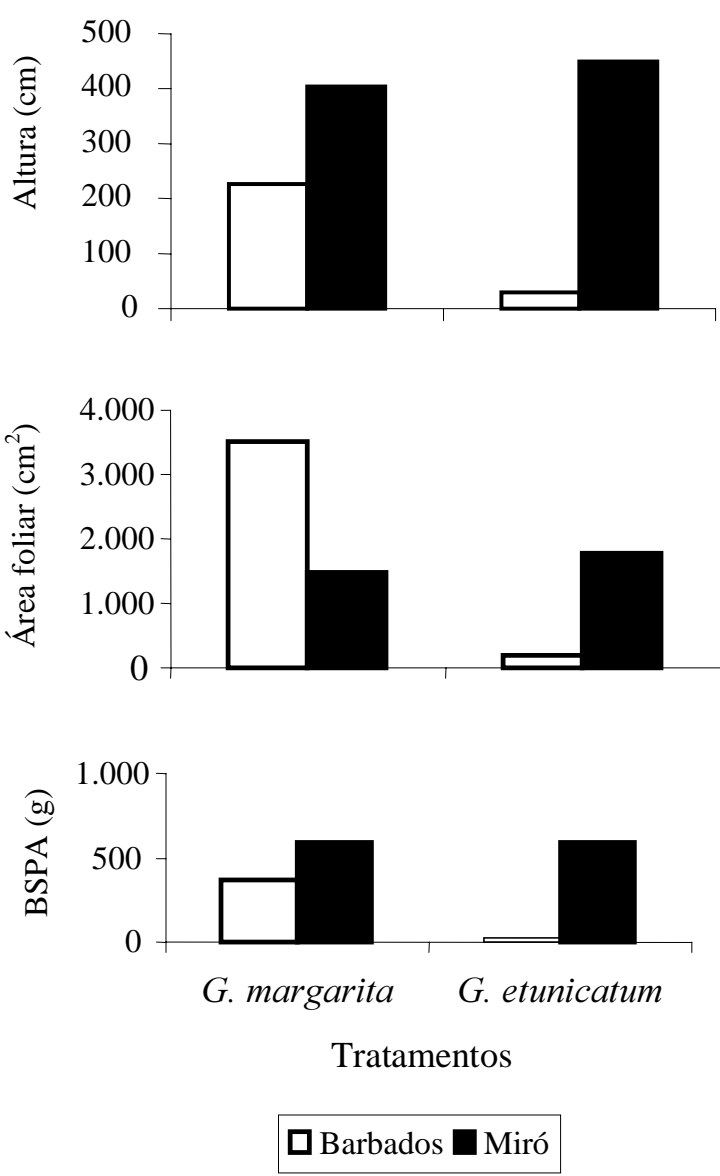

Figura 4. Incrementos na altura, área foliar e biomassa seca da parte aérea (BSPA) de dois genótipos de aceroleira, Barbados e Miró, obtidos aos 110 dias após a inoculação dos fungos micorrízicos arbusculares Gigaspora margarita e Glomus etunicatum. 
rando os tratamentos inoculados e os não inoculados. Isso ocorreu possivelmente porque a quantidade de $\mathrm{P}$ no solo era muito baixa. Resultados divergentes foram relatados por Chu (1993): aceroleiras inoculadas com G. margarita apresentaram quantidades maiores de P na parte aérea. Dados similares foram relatados em plantas de tangerina 'Cleópatra' (Cardoso \& Lambais, 1993). Em estudos com diferentes genótipos de bananeira, Declerck et al. (1995) observaram que a concentração de $\mathrm{P}$ variou de acordo com a cultivar utilizada. Entretanto, Silva \& Siqueira (1991) constataram que a quantidade de $\mathrm{P}$ em folhas de abacateiro e mangueira variou de acordo com o fungo inoculado. Resultados semelhantes foram descritos por Chu (1999), em plantas de açaizeiro.

O aumento no crescimento da planta, promovido pela associação micorrízica, é devido sobretudo à maior absorção de nutrientes (Cardoso \& Lambais, 1993). Por outro lado, o crescimento de ambos os simbiontes é influenciado pelo genótipo da planta hospedeira, pela espécie do fungo e pelo solo, mas não está necessariamente relacionado à porcentagem de colonização das raízes; além disso, em dado nível de colonização, a eficiência da absorção de nutrientes pode ser afetada pelos parâmetros da troca de nutrientes na interface fungo-raiz e pela extensão, viabilidade e capacidade de transporte das hifas externas (Marschner \& Dell, 1994).

A presença de algumas estruturas fúngicas nas raízes e na rizosfera das plantas sem inoculação pode ter sido conseqüência de contaminação, ocorrida durante o período de enraizamento das estacas, através do vento ou pela água de irrigação (Weber \& Amorim, 1994), uma vez que o solo utilizado no experimento estava comprovadamente esterilizado. Também pode ter havido reinvasão de propágulos de FMA, tal como referido por Menge (1982), a qual pode ocorrer entre dois a treze meses após a desinfestação do solo com brometo de metila por meio de estruturas de FMA que escaparam à esterilização.

A porcentagem de colonização por FMA variou entre os dois genótipos (Tabela 1). As plantas do genótipo Barbados apresentaram colonização estatisticamente maior quando associadas a G. margarita, em comparação com as colonizadas por G. etunicatum e as não colonizadas. No genótipo Miró a colonização das plantas com G. margarita também foi superior, embora a diferença em relação à associação com G. etunicatum tenha sido menor, porém mesmo assim significativa. Para os dois tratamentos com FMA, a colonização das raízes das plantas do genótipo Miró foi estatisticamente superior à das raízes do genótipo Barbados (Tabela 1). Chu (1993) não observou diferença significativa na porcentagem de colonização entre raízes de aceroleiras associadas com FMA, porém a inoculação de G. margarita proporcionou aumento de alguns parâmetros de crescimento. Neste trabalho, a porcentagem de colonização variou de acordo com o genótipo e o fungo inoculado; resultados similares foram descritos por González-Chávez \& FerreraCerrato (1987) em cultivares de morango associadas com FMA.

A colonização micorrízica proporcionou aumento de todos os parâmetros de crescimento das plantas aqui estudadas, fato também observado por Declerck et al. (1995), os quais constataram que a colonização variou de acordo com a cultivar estudada. Estaún et al. (1987), no entanto, descreveram que a porcentagem de colonização, em três cultivares de ervilha, variou de acordo com os fungos inoculados e não com as cultivares.

Em relação à produção de esporos, diferenças significativas foram observadas apenas na rizosfera das plantas do genótipo Miró associadas com G. margarita, as quais apresentaram maior densidade de esporos do que as da rizosfera do genótipo Barbados (Tabela 1).

O grau de correlação pode indicar a existência ou não de dependência entre as características da planta e do FMA, sendo completamente independentes as características que não apresentam correlação (Bentivenga et al., 1997).

Foram observadas correlações altamente significativas, que variaram de médias a fortíssimas, entre algumas características de crescimento da planta (altura, biomassa seca da parte aérea e área foliar) e entre estas e a densidade de esporos no solo (Tabela 2). Não houve correlação entre densidade de esporos de FMA na rizosfera e colonização de raízes, como observado também em videiras por Schubert et al. (1988). Parâmetros de colonização e 
densidade de esporos não são dependentes um do outro, embora se entenda que possam estar relacionados, em razão das condições tanto dos simbiontes como ambientais (Douds Junior \& Schenck, 1990).

Correlações envolvendo características do FMA e das plantas foram significativas apenas entre densidade de esporos e área foliar, altura das plantas e biomassa seca da parte aérea (Tabela 2). Por outro lado, a porcentagem de colonização não se correlacionou com quaisquer dos parâmetros de crescimento das plantas.

As plantas do genótipo Barbados associadas com G. margarita apresentaram maior número de correlações altamente significativas, com $\mathrm{r}^{2}$ variando de 0,94 a 0,97, entre os parâmetros de crescimento e entre estes e a densidade de esporos de FMA. Quando as plantas deste mesmo genótipo foram colonizadas por G. etunicatum, houve correlação apenas entre altura e biomassa seca. No genótipo Miró, maior número de correlações também foi encontrado quando as plantas foram colonizadas por G. margarita; porém, apenas três correlações entre parâmetros de crescimento da planta foram significativas: área foliar x biomassa da parte aérea e altura da planta. Foi observada apenas uma correlação envolvendo características do FMA e da planta: densidade de esporos x biomassa seca da parte aérea (Tabela 2). Nas plantas associadas com G. etunicatum houve correlação significativa apenas entre área foliar e biomassa seca das plantas, no genótipo Miró, e entre a altura e a biomassa seca no genótipo Barbados (Tabela 2). Resultados similares com aceroleiras, onde não houve correlação entre porcentagem de colonização e produção de matéria seca, também foram relatados por Chu (1993). Os resultados não revelaram correlação significativa entre colonização e conteúdo de $\mathrm{P}$ na parte aérea das plantas estudadas. Em plantas de açaizeiro, foram observadas correlações significativas entre resposta de crescimento, porcentagem de colonização e conteúdo de nutrientes (Chu, 1999).

As respostas de crescimento das plantas variaram de acordo com o genótipo estudado e com o FMA inoculado. Os mecanismos fisiológicos e genéticos que envolvem os diferentes processos e levam à colonização micorrízica ainda estão pouco entendidos; no entanto, alguns autores citam que a colonização representa significante custo de $\mathrm{C}$, que pode ser regulado pelo genótipo do hospedeiro (Graham \& Eissenstat, 1994).

Nos experimentos de Chu (1993) foram utilizados como inóculo, em aceroleiras, $30 \mathrm{~g}$ de solo contendo aproximadamente 543 esporos de G. margarita e 1.164 de Acaulospora longula, sendo obtidos valores similares ou até inferiores aos aqui relatados com a inoculação de 200 esporos, em relação à altura, biomassa e porcentagem de colonização, após praticamente o mesmo tempo de inoculação. Assim,

Tabela 2. Estimativas dos coeficientes de correlação entre as características de crescimento da planta e as referentes aos fungos micorrízicos arbusculares Gigaspora margarita $(\mathrm{Gm})$ e Glomus etunicatum $(\mathrm{Ge})$, nos genótipos de aceroleiras, Barbados (B) e Miró (M), aos 110 dias após a inoculação.

\begin{tabular}{|c|c|c|c|c|c|c|}
\hline \multirow[t]{2}{*}{ Características $^{(1)}$} & \multicolumn{3}{|c|}{ Barbados } & \multicolumn{3}{|c|}{ Miró } \\
\hline & Não-inoculado & G. margarita & G. etunicatum & Não-inoculado & G. margarita & G. etunicatum \\
\hline AF versus BPA & $-0,1163^{\mathrm{ns}}$ & $0,9421^{* *}$ & $0,6261^{\mathrm{ns}}$ & $-0,3135^{\mathrm{ns}}$ & $0,6361^{*}$ & $0,8119^{* *}$ \\
\hline $\mathrm{AF}$ versus $\mathrm{CR}$ & $0,4910^{\mathrm{ns}}$ & $0,6046^{\mathrm{ns}}$ & $0,4485^{\mathrm{ns}}$ & $0,3037^{\mathrm{ns}}$ & $-0,2508^{\mathrm{ns}}$ & $0,3518^{\mathrm{ns}}$ \\
\hline $\mathrm{AF}$ versus $\mathrm{DE}$ & $0,0491^{\mathrm{ns}}$ & $0,9473^{* *}$ & $-0,3638^{\mathrm{ns}}$ & $0,3144^{\mathrm{ns}}$ & $0,0963^{\mathrm{ns}}$ & $-0,3799^{\mathrm{ns}}$ \\
\hline $\mathrm{AF}$ versus $\mathrm{AP}$ & $0,3756^{\mathrm{ns}}$ & $0,9631^{* *}$ & $0,6244^{\mathrm{ns}}$ & $-0,3120^{\mathrm{ns}}$ & $0,8673^{* *}$ & $0,5797^{\mathrm{ns}}$ \\
\hline $\mathrm{AP}$ versus $\mathrm{BPA}$ & $0,1242^{\mathrm{ns}}$ & $0,9500^{* *}$ & $0,8198^{* *}$ & $0,5388^{\mathrm{ns}}$ & $0,6600^{*}$ & $0,5268^{\mathrm{ns}}$ \\
\hline CR versus BPA & $-0,1776^{\mathrm{ns}}$ & $0,5557^{\mathrm{ns}}$ & $0,0932^{\mathrm{ns}}$ & $0,3047^{\mathrm{ns}}$ & $0,3698^{\mathrm{ns}}$ & $-0,0964^{\mathrm{ns}}$ \\
\hline CR versus $\mathrm{AP}$ & $0,2382^{\mathrm{ns}}$ & $0,5809^{\mathrm{ns}}$ & $0,1449^{\mathrm{ns}}$ & $0,1609^{\mathrm{ns}}$ & $-0,2970^{\mathrm{ns}}$ & $-0,2216^{\mathrm{ns}}$ \\
\hline $\mathrm{DE}$ versus $\mathrm{AP}$ & $-0,2764^{\mathrm{ns}}$ & $0,9747^{* *}$ & $0,2124^{\mathrm{ns}}$ & $0,1340^{\mathrm{ns}}$ & $0,1055^{\mathrm{ns}}$ & $-0,0835^{\mathrm{ns}}$ \\
\hline DE versus BPA & $0,4006^{\mathrm{ns}}$ & $0,9687^{* *}$ & $0,2722^{\mathrm{ns}}$ & $-0,1258^{\mathrm{ns}}$ & $0,7420^{*}$ & $-0,3913^{\mathrm{ns}}$ \\
\hline DE versus CR & $-0,0788^{\mathrm{ns}}$ & $0,5793^{\mathrm{ns}}$ & $-0,4178^{\mathrm{ns}}$ & $0,3214^{\mathrm{ns}}$ & $0,5429^{\mathrm{ns}}$ & $-0,2175^{\mathrm{ns}}$ \\
\hline
\end{tabular}

${ }^{(1)} \mathrm{AF}$ : área foliar; BPA: biomassa seca da parte aérea; AP: altura da planta; CR: porcentagem de colonização de raízes; DE: densidade de esporos na rizosfera. ${ }^{\text {ns }}$ Não-significativo. ${ }^{*} \mathrm{e} * *$ Significativo a $5 \%$ e a $1 \%$ de probabilidade, respectivamente, pelo teste $\mathrm{F}$. 
aparentemente não é necessário inocular mais de 200 esporos de FMA para obter respostas da aceroleira à micorrização. Estaún et al. (1987), embora tenham constatado que a infectividade dos fungos micorrízicos utilizados tenha sido independente da cultivar, mostraram que a efetividade em promover o crescimento das plantas variou com o genótipo estudado.

\section{Conclusões}

1. O tempo de produção de mudas de aceroleira pode ser reduzido à metade com a aplicação de FMA, após o enraizamento das estacas.

2. A inoculação de G. margarita e G. etunicatum promove o crescimento das plantas do genótipo Miró; as plantas do genótipo Barbados são mais beneficiadas pela inoculação de G. margarita.

3. A eficiência da associação entre FMA e aceroleiras é regulada pelos genótipos dos dois parceiros micorrízicos.

4. O uso de inóculo constituído por 200 esporos de FMA é suficiente para promover o crescimento diferenciado de aceroleiras colonizadas em relação às não colonizadas.

\section{Agradecimentos}

Ao Conselho de Desenvolvimento Científico e Tecnológico (CNPq), pelo apoio financeiro; a Venézio Felipe dos Santos (IPA), pelas análises estatísticas; aos colegas André Dias de Azevedo Neto (UFRPE) e Ana Célia Rodrigues de Athayde (UFPB), pela ajuda na elaboração dos gráficos.

\section{Referências}

ARAÚJO, A. P.; SILVA, E. M. R.; ALMEIDA, D. L. Efetividade de fungos endomicorrízicos em tomateiros em diferentes níveis de fósforo no solo. Revista Brasileira de Ciência do Solo, Campinas, v. 18, p. 193-199, 1994.

BENINCASA, M. M. P. Análise de crescimento de plantas. Jaboticabal : FUNEP, 1988. 42 p.

BENTIVENGA, S. P.; BEVER, J. D.; MORTON, J. B. Genetic variation of morphological characters within a single isolate of the endomycorrhizal fungus Glomus clarum (Glomaceae). American Journal of Botany, Columbus, v. 84, n. 9, p. 1211-1216, 1997.
CARDOSO, E. J. B. N.; LAMBAIS, M. R. Efeito de aldicarb e fosetil-al no desenvolvimento e na colonização micorrízica de tangerina Cleópatra. Revista Brasileira de Ciência do Solo, Campinas, v. 17, p. 179-184, 1993.

CAVALCANTE, U. M. T. Efeitos da associação de fungos micorrízicos arbusculares com o maracujazeiro amarelo (Passiflora edulis Sims. f. flavicarpa Deg.). Recife : UFPE, 1999. 139 p. Tese de Doutorado.

CHU, E. Y. Inoculação de fungos micorrízicos arbusculares em plântulas de acerola (Malpighia glabra L.). Belém : Embrapa-CPATU, 1993. 15 p. (Embrapa-CPATU. Boletim de Pesquisa, 149).

CHU, E. Y. The effects of arbuscular mycorrhizal fungi inoculation on Euterpe oleracea Mart. seedlings. Pesquisa Agropecuária Brasileira, Brasília, v. 34, n. 6, p. 1019 1024, jun. 1999.

DECLERCK, S.; PlENCHETTE, C.; STRULlU, D. G. Mycorrhizal dependency of banana (Musa acuminata, AAA group) cultivar. Plant and Soil, Dordrecht, v. 176, p. 183-187, 1995.

DOUDS JUNIOR, D. D.; SCHENCK, N. C. Relationship of colonization and sporulation by VA mycorrhizal fungi to plant nutrient and carbohydrate contents. New Phytologist, Cambridge (Inglaterra), v. 116, p. 621-627, 1990.

ESTAÚN, V.; CALVET, C.; HAYMAN, D. S. Influence of plant genotype on mycorrhizal infection: response of three pea cultivars. Plant and Soil, Dordrecht, v. 103, p. 295-298, 1987.

GERDEMANN, J. W.; NICOLSON, T. H. Spores of mycorrhizal Endogone species extracted from soil by wet sieving and decanting. Transactions of the British Mycological Society, Cambridge (Inglaterra), v. 46, p. 235-244, 1963.

GIANINAZZI-PEARSON, V. Plant cell response to arbuscular mycorrhizal fungi: getting to the roots of the symbiosis. Plant Cell, Rockville, v. 8, p. 1871-1883, 1996.

GIOVANNETTI, M.; MOSSE, B. An evaluation of techniques for measuring vesicular arbuscular mycorrhizal infection in roots. New Phytologist, Cambridge (Inglaterra), v. 84 , p. $489-500,1980$. 
GONZAGA NETO, L.; SOARES, J. M. Acerola para exportação: aspectos técnicos da produção. Brasília : EmbrapaSPI, 1994. 43 p. (Publicações Técnicas Frupex, 10).

GONZÁLEZ-CHÁVEZ, M. C.; FERRERA-CERRATO, R. Efectos del captan y la endomicorriza (V-A) sobre el desarrollo de fresa proveniente del cultivo in vitro. Revista Latinoamericana de Microbiología, México, v. 29, p. 193-199, 1987.

GONZÁLEZ-CHÁVEZ, M. C.; FERRERA-CERRATO, R. Effect of vesicular-arbuscular mycorrhizae on tissue culture-derived plantlets of strawberry. HortScience, Alexandria, v. 8, n. 25, p. 903-905, 1990.

GRAHAM, J. H.; EISSENSTAT, D. M. Host genotype and the formation and function of VA mycorrhizae. Plant and Soil, Dordrecht, v. 159, p. 179-185, 1994.

JAIZME-VEGA, M. C. J.; AZCÓN, E. R. Responses of some tropical and subtropical cultures to endomycorrhizal fungi. Mycorrhiza, Berlin, v. 5, p. 213-217, 1995.

JENKINS, W. R. A rapid centrifugal-flotation technique for separating nematodes from soil. Plant Disease Reporter, St. Paul, v. 48, p. 692, 1964.

MARSCHNER, H.; DELL, B. Nutrient uptake in mycorrhizal symbiosis. Plant and Soil, Dordrecht, v. 159, p. 89-102, 1994.
MENGE, J. A. Effect of soil fumigant and fungicides on vesicular-arbuscular fungi. Phytopathology, St. Paul, v. 72, p. $1125-1182,1982$

PHILLIPS, J. M.; HAYMAN, D. S. Improved procedures for clearing roots and staining parasitic and vesicular arbuscular mycorrhizal fungi for rapid assessment of infections. Transactions of the British Mycological Society, Cambridge (Inglaterra), v. 55, n. 1, p. 158-161, 1970.

RIBEIRO, M. E. Estatística descritiva. João Pessoa : Comissão Estadual de Planejamento Agrícola, 1970. 166 p.

SARRUGE, J. R.; HAAG, H. P. Análises químicas em plantas. Piracicaba : ESALQ, 1974. 56 p.

SCHUBERT, A.; CAMMARATA, S.; EYNARD, I. Growth and root colonization of grapevines inoculated with different mycorrhizal endophytes. HortScience, Alexandria, v. 23, n. 2, p. 302-303, 1988.

SILVA, L. F. C.; SIQUEIRA, J. O. Crescimento e teores de nutrientes de mudas de abacateiro, mangueira e mamoeiro sob influência de diferentes espécies de fungos micorrízicos vesículo-arbusculares. Revista Brasileira de Ciência do Solo, Campinas, v. 15, p. 283-285, 1991.

WEBER, O. B.; AMORIM, S. M. C. Adubação fosfática e inoculação de fungos micorrízicos vesicular arbusculares em mamoeiros 'Solo'. Revista Brasileira de Ciência do Solo, Campinas, v. 18, p. 187-191, 1994. 